\title{
Kinematic bidimensional analysis of the propulsion technique in wheelchair rugby athletes
}

\author{
Sara Maria Franchin (1), Federico Giordani (1), Michele Tonellato (1), Michael \\ Benazzato (2), Giuseppe Marcolin (2), Paolo Sacerdoti (2), Francesco Bettella (2), \\ Alfredo Musumeci (1), Nicola Petrone (2), Stefano Masiero (1) \\ (1) Physical medicine and rehabilitation School, Neuroscience Department, Padova University, \\ Italy; (2) Sports and Rehabilitation Engineering Laboratory, Padova University, Italy \\ This article is distributed under the terms of the Creative Commons Attribution Noncommercial License (CC BY-NC 4.0) which permits \\ any noncommercial use, distribution, and reproduction in any medium, provided the original author(s) and source are credited.
}

\begin{abstract}
Wheelchair rugby is a sport ideated for individuals with cervical spinal cord injury (CSCI) which is extremely important for maintaining their neuromuscular abilities and improving their social and psychological wellbeing. However, due to the frequent changes in direction and speed it considerably stresses the players' upper limbs. 13 athletes have undergone two sports-related tests on an inertial drum bench and several kinematic parameters have been registered. Most athletes use a semi-circular pattern which is considered protective for the upper limb. With increasing speed, range of motion (ROM) increases. Release angles increment and contact angles reduce, displacing the push angle forward to increase speed. Instead, the more anterior late push angle used to increase velocity is a factor which further loads the shoulder joint. However, other factors affecting propulsion technique, such as posture and wheelchair set up should be studied to further reduce loading on the upper limb.
\end{abstract}

Key Words: propulsion kinematics, Paralympic sports, elite athletes, wheelchair rugby, wheelchair propulsion

Eur J Transl Myol 30 (1): 129-133, 2020

Wheelchair rugby (WRugby) was developed in Canada in the 1970's by athletes with quadriplegia. It is a Paralympic team sport since Sydney 2000 Para Games. ${ }^{1}$ It's well known that staying active after a Spinal Cord Injury (SCI) is important for maintaining physical capacity, but also for mental and emotional well-being. ${ }^{2}$ Evidence shows that regular physical activity is an effective way of improving fitness in the SCI population as well as promoting functional independence. ${ }^{3}$ Patients' perceived benefits of sports activity include a feeling of increased fitness, increased social interactions, improved quality of life, muscle strength and confidence and better physical recovery. ${ }^{4}$ Sports practice represents a risk factor for both overuse and trauma disorders, especially to the upper limbs, that are used for all their daily life activities. The repeated performance of upper limb, weight-bearing activities such as wheelchair propulsion, transfers, and raised ischial pressure reliefs ("weight shifts"), as well as reaching from a seated position in the wheelchair in environments designed for nondisabled individuals, places a great deal of stress on the bones, joints, and soft tissues of the shoulder complex, placing these structures at significant risk for overuse and injury. ${ }^{5}$
Wheelchair rugby a discipline with high risk of injury. Indeed it resulted as fifth most injury-prone sport in the London 2012 Summer Paralympic game. ${ }^{6}$ Biomechanical research is considered a very important contribute to performance and athlete wellbeing as it gains insight in technical optimization, injury prevention and classification in Paralympic sports. ${ }^{7}$ Many researchers have studied the biomechanical factors and underlying musculature involved during standard wheelchair propulsion, ${ }^{8}$ whereas the propulsion technique used during sports such as wheelchair rugby is still being investigated. We here report preliminary results of a project conducted by an interdisciplinary research team of professionals which included doctors, physiotherapists, engineers, psychologists and physical education students. Aim of study was the evaluation of the propulsion kinematic and wheelchair propulsion characteristics among the athletes of the Italian National Wheelchair rugby team. ${ }^{9}$

\section{Materials and Methods}

The subjects included were 13 athletes from the Italian National Wheelchair rugby team in which 12 had Spinal 


\begin{tabular}{|c|c|c|c|c|c|c|c|}
\hline \multicolumn{8}{|c|}{ Table 1: Subject presentation } \\
\hline Athlete & $\begin{array}{l}\text { Classification Points } \\
\text { (level of disability) }\end{array}$ & Pathology & Lesion level & Sprint test & Wingate test & Motion Capture & $\begin{array}{c}\text { Athlete } \\
\text { comparison }\end{array}$ \\
\hline P.S. & 0.5 & SCI & $\mathrm{C} 5-\mathrm{C} 6$ & $\mathrm{x}$ & $\mathrm{x}$ & & $\mathrm{x}$ \\
\hline A.F. & 0.5 & SCI & $\mathrm{C} 5$ & $\mathrm{x}$ & $\mathrm{x}$ & $\mathrm{x}$ & $\mathrm{x}$ \\
\hline P.F. & 1 & SCI & $\mathrm{C} 5-\mathrm{C} 6$ & & $\mathrm{x}$ & & $\mathrm{x}$ \\
\hline H.K. & 1 & SCI & C5-C6 & $\mathrm{x}$ & $\mathrm{x}$ & $\mathrm{x}$ & $\mathrm{x}$ \\
\hline G.T. & 1 & SCI & C6-C7 & & $\mathrm{x}$ & & $\mathrm{x}$ \\
\hline S.P. & 1.5 & SCI & C6 & $\mathrm{x}$ & $\mathrm{x}$ & & $\mathrm{x}$ \\
\hline A.D. & 1.5 & SCI & $\mathrm{C} 7$ & $\mathrm{x}$ & $\mathrm{x}$ & & $\mathrm{x}$ \\
\hline D.G. & 1.5 & SCI & C6-C7 & $\mathrm{x}$ & $\mathrm{x}$ & $\mathrm{x}$ & $\mathrm{x}$ \\
\hline L.V. & 2.5 & SCI & $\mathrm{C} 5-\mathrm{C} 7$ & & $\mathrm{x}$ & & $\mathrm{x}$ \\
\hline M.B. & 2.5 & SCI & C7-T1 & $\mathrm{x}$ & $\mathrm{x}$ & $\mathrm{x}$ & \\
\hline N.T. & 3.0 & SCI & $\mathrm{C} 7$ & & $\mathrm{x}$ & & $\mathrm{x}$ \\
\hline A.B. & 3.5 & SCI & $\mathrm{T} 6-\mathrm{T} 7$ & $\mathrm{x}$ & $\mathrm{x}$ & $\mathrm{x}$ & \\
\hline P.M. & 3.5 & $\begin{array}{l}\text { Cerebral } \\
\text { Palsy }\end{array}$ & - & $\mathrm{x}$ & $\mathrm{x}$ & $\mathrm{x}$ & \\
\hline
\end{tabular}

Cord Injury (SCI) and 10 had Cervical Spinal Cord Injury (CSCI). Table 1 displays the tests available for each subject and specific information for each athlete. The level of disability was evaluated using the sport classification (IWRF 2005-2017).

\section{Instrumentation and tests}

1. -An inertial drum bench

2. -BTS Bioengineering Smart DX-6000

Optoelectronics MotionCapture 3D system with 8 infrared cameras.

3. -A Canon Powershot SX240 HS camera

4. -Computer software Kinovea, 0.8.25.0 version for Windows was used to analyze the videos taken of the athletes during the tests' execution.

Athletes carried out 2 sports-specific dynamic tests on the drum bench:

1. Sprinting test over 20 meters, measured using the drum bench

2. Wingate test10: a sprint test with an applied resistance exerted by the drum bench.

All tests were carried out on the athletes' personal rugby wheelchair. Athletes were filmed as they performed the tests. Data analysis were analyzed with Kinovea software. Three push cycles were chosen (one at beginning, one in the middle and one at the end of the test) to have an example of the propulsive stroke at the different speeds obtained in the sprint test. For each video the following parameters were considered:
1. "Absolute arm angle": the angle comprised by the segment built on the arm with the vertical line originating from the elbow marker.

2. "Arm to forearm angle": the angle made up by the arm and forearm created by elbow flexion and extension.

3. "Elbow flexion angle"

4. "Contact angle" (Figure 1a)

5. "Release angle" (Figure 1b)

6. "Total Push angle" (Figure 1c)

Each of these parameters was taken for every frame of the video throughout the whole push cycle and recorded on an Excel worksheet.

\section{Comparison between athletes}

The results for absolute arm angle and elbow flexion were compared amongst different athletes for each part of each test: sprint start, sprint midway, sprint end, Wingate start, Wingate midway and Wingate end. Graphs were plotted of the angles indicating the flexionextension pattern used by the different athletes in each part of the test, differentiating between Sprint and Wingate. Furthermore, numerical values of maximum, minimum and mean elbow flexion and extension values at start, middle and final parts of Wingate and Sprint tests were compared amongst different athletes. Similarly, contact, release and total push angles were compared between different athletes. All calculations were done using Excel computer software for Windows.

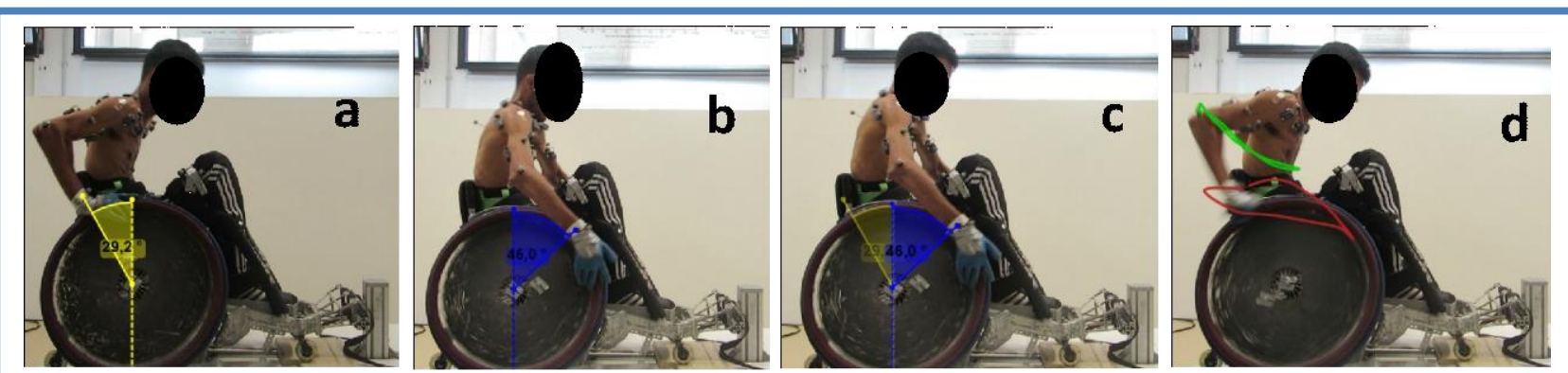

Fig 1. a: contact angle; $b$ : release angle, $c:$ total push angle, $d:$ wrist (red) and elbow (green) trajectories 


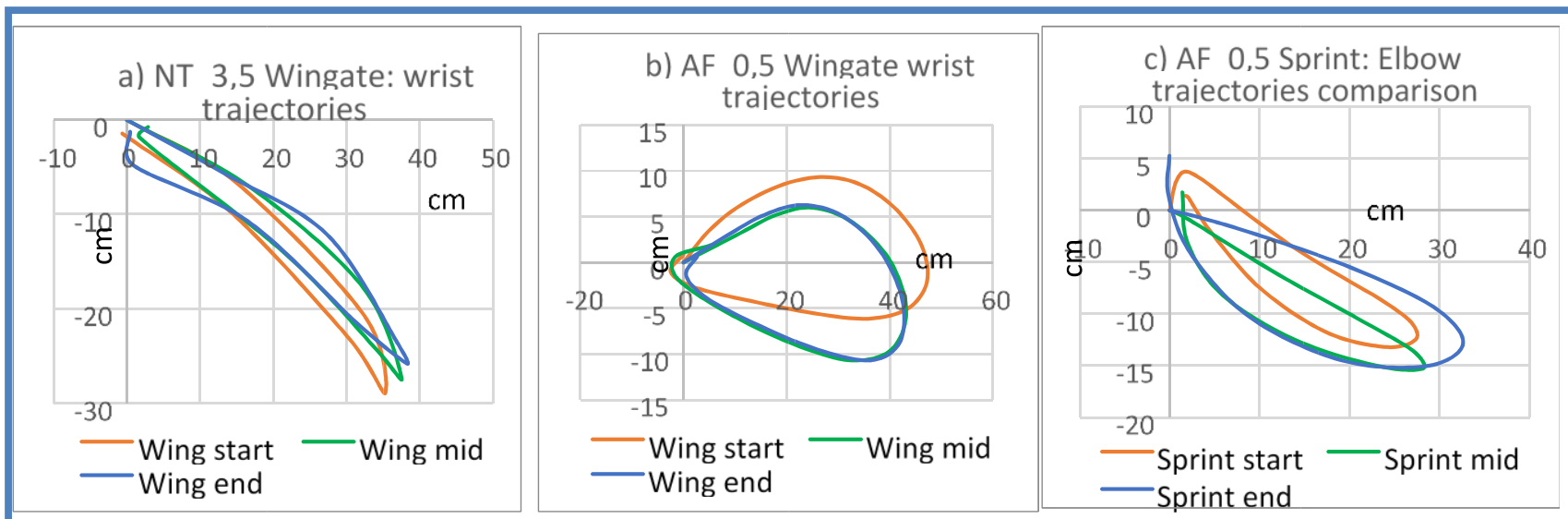

Fig 2. $\quad a$ and $b$ : wingate wrist trajectories of athletes by High level $(N T)$ and low level $(A F)$ of disability respectively; c: sprint elbow trajectory of the sprint test of athlete by low level disability.

\section{Results and Discussion}

Athletes' analyses are reported in Figure 2.

\section{Trajectories}

Most athletes used a propulsion technique that reminds of the semi-circular pattern, ${ }^{11}$ particularly those with greater levels of disability. This suggests that it is the easiest to achieve and requires less motor control. Furthermore, it allows to use a greater portion of the push rim to carry out the stroke and reach a considerable speed by spreading the force applied on a greater surface. Its elliptical shape reduces the stress applied to the joints as it doesn't include abrupt changes in direction: it is in fact considered the most protective for the upper limb. Players with greater motor abilities tend to use the arching pattern which is more efficient and includes a sharp alternation of flexion and extension. The welldefined trajectory suggests the need for greater muscle coordination and precision in muscle activation and control to maintain the strict flexion-extension pattern. However, this modality is associated to abrupt changes in direction which are considered stressful to the upper extremity joints. ${ }^{11}$

\section{Sprint test}

Overall ROM at the elbow increases for most athletes from the start $\left(68,4^{\circ} \pm 14,3^{\circ}\right)$ to the end $\left(76^{\circ} \pm 10,98^{\circ}\right)$. Lower-classified players exhibit rather small peak extension values and greater elbow flexion values whereas subjects with higher classification scores use progressively greater elbow extension and less elbow flexion. This can be explained by the fact that low-point subjects with lesion level C5 or C5-C6 are unable or only partially capable of recruiting the triceps and tend to use greater elbow flexion at the start of the push phase to maximize biceps function. ${ }^{12}$ In contrast, players with better motor function utilize a smaller elbow flexion at initial contact and probably use a forward displacement of the trunk to aid the propulsion technique. This is consistent with the lesion level and a greater muscle recruitment on the upper trunk. ${ }^{12}$ According to Van der Woude et al. studies, a range between $94^{\circ}$ and $143^{\circ}$ of elbow flexion is effective in giving ideal long, smooth strokes in normal wheelchair users. ${ }^{13}$ The athletes analyzed, though, use largely smaller elbow extension and greater elbow flexion, for an overall range between $43,1^{\circ} \pm 4,52^{\circ}$ and $116,8^{\circ} \pm 0,79^{\circ}$. This is probably given by their inability to recruit upper-limb distal muscles, especially the triceps.

\section{Wingate test}

The range of motion seems to vary less in amplitude compared to sprint test $\left(75,9^{\circ} \pm 18,68^{\circ}\right.$ at the start, $74,7^{\circ}$ $\pm 18,1^{\circ}$ at the end), probably due to a greater difficulty in overcoming the additional resistance applied. The most significant finding was that there is a great variability between athletes in the strategies used to overcome this resistance: most subjects display an increase in ROM between the start and the middle of the test, probably due to muscular and cardiovascular fatigue; some displayed a decrease with a consequent increase in ROM which might be caused by an initial difficulty in accelerating and overcoming the resistance at the same time. The overall mean percentage time spent pushing during Wingate, $50,1 \%$, was greater than the percentage push phase of the Sprint test, $44,4 \%$ : at the start the percentage time spent pushing is similar in both tests, it then decreases throughout the test but during the Sprint test the decrease is larger. Furthermore, two subjects changed their style of push: one from semi-circular to doubleloop-over and the second from semi-circular to arcing pattern. While the first subject has a greater level of disability and exhibits this change both in Wingate and Sprit tests, suggesting this is a strategy used to increase speed; the second only changes to arcing pattern in the sprint test, suggesting the semi-circular pattern is more useful when having to overcome higher loads and maintain a high speed at the same time.

\section{Push and contact angles}

In the sprint test there seems to be an overall increase in 
release angles with a mean increment of $8,5^{\circ} \pm 3,7^{\circ}$ and reduction in contact angles of an average of $9,1^{\circ} \pm 5,2^{\circ}$ resulting in an overall increase in total push angles which is consistent with Haydon et al. study. ${ }^{11}$ During the Wingate test, instead, contact angles seem to remain similar, with a decrease, at the end of the test of contact, release and total push angles. This might be a strategy to achieve a greater velocity during wheelchair propulsion. Absolute arm angles also remain rather similar with a mean ROM of $82,1^{\circ} \pm 15,5^{\circ}$ and $82,25^{\circ} \pm 14,35^{\circ}$ at start and end. Unfortunately, this condition has been related to a higher amount of forces exerted on the shoulder ${ }^{14}$. An efficient sprinting technique is very important in wheelchair rugby as it allows to reach quickly the opposing team's line to score points, however it is in contrast with shoulder pain prevention.

In conclusion, the results obtained allowed the identification of diversities amongst athletes with different neuromuscular abilities and the overall techniques used to perform sports tasks. The study reveals that most wheelchair rugby athletes use a semicircular style of push, especially lower point players. In literature this is regarded as the least dangerous technique for upper limb disorders. High point players tend to use an arcing pattern and more anteriorly displaced angles that promote a faster speed but are potentially damaging Prevention should stand on compromise between protective technique and best sport performance. Since the results reported in this first report are very interesting, it will be worth to involve a greater number of athletes in the following phases of the project.

\section{List of acronyms}

CSCI - cervical spinal cord injury

IWRF - International Wheelchair Rugby Federation

ROM - range of motion

SCI - Spinal Cord Injury

WRugby - Wheelchair rugby

\section{Authors contributions}

SMF and FG document production and clinical evaluation; MT clinical analysis; MB, GM, FB and PS kinematic analysis and test assessment; MA, NP and SM study conception and critical revision.

\section{Acknowledgments}

This work is a part of a research project entitled "Progetto finalizzato al miglioramenton delle capacità neuromuscolari residue in atleti disabili nella pratica sportiva del rugby in carrozzina" that was supported by Fondazione Cassa di Risparmio di Padova e Rovigo, Opera Immacolata Concezione, Fondazione, Federazione Italiana Sport Paralimpici e Sperimentali.

\section{Funding}

This study was supported by Fondazione Cassa di Risparmio di Padova e Rovigo and Opera Immacolata Concezione

\section{Conflict of Interest}

The authors declare they have no financial, personal, or other conflicts of interest.

\section{Ethical Publication Statement}

We confirm that we have read the Journal's position on issues involved in ethical publication and affirm that this report is consistent with those guidelines.

\section{Corresponding Author}

Federico Giordani, Department of Neurosciences, Physical medicine and rehabilitation School, Padova University, Italy. ORCID iD: 0000-0001-7598-8189

Email: federico.giordi@gmail.com

E-mail and ORCID iD of co-authors

Sara Maria Franchin: sara.mfranchin@gmai.com Michele Tonellato: michele.tonellato@gmail.com ORCID iD: 0000-0003-3041-1647

Michael Benazzato: michael.benazzato@gmail.com Giuseppe Marcolin: giuseppe.marcolin@unipd.it

Paolo Sacerdoti: paolosacerdoti@gmail.com

Francesco Bettella: fra.bettella@gmail.com ORCID iD: 0000-0003-4037-1888

Alfredo Musumeci: alfredomusumeci@yahoo.com ORCID iD: 0000-0003-4213-5440

Nicola Petrone: nicola.petrone@unipd.it

ORCID iD: 0000-0002-6638-484X

Stefano Masiero: stefano.masiero@unipd.it

ORCID iD: 0000-0002-0361-4898

\section{References}

1. International Wheelchair Rugby Federation. Introduction to wheelchair rugby. Available at: http://www.iwrf.com./resources/ iwrf_docs/Introduction-to-Wheelchair-Rugby2012.pdf. Accessed September 5, 2015

2. Jackson RW. Sport for the spinal paralysed person. Paraplegia 1987;25:301-4.

3. Hicks AL, Martin KA, Ditor DS, et al. Long term exercise training in persons with spinal cord injury: effects on strength, arm ergometry performance and psychological well-being". Spinal Cord 2011;41:34-43.

4. O'Neil SB, Maguire S. Patient perception of the impact of sporting activity on rehabilitation in a spinal cord injuries unit. Spinal Cord 2004;42,627630

5. Bayley J, Cochran T, Sledge C. The weight-bearing shoulder. The impingement syndrome in paraplegics. J Bone Joint Surg 1987;69:676-8.

6. Bauerfeind J, Koper M, Weiczorek J, et al. Sports Injuries in Wheelchair rugby -A Pilot Study. J Hum Kinet 2015;48:123-32.

7. Morrien F, Taylor JDM, Hettinga TF. Biomechanics in Paralympics: Implications for Performance. Human Kinetics Journals 2016;12:578-89.

8. Rao SS, Bontrager EL, Gronley JK, et al. Three- 


\section{Shoulder pain in wheelchair rugby athletes}

Eur J Transl Myol 30 (1): 129-133, 2020

Dimensional Kinematics of Wheelchair Propulsion. IEEE Trans Rehabil Eng 1996;4:152-60

9. OIC onlus (2015), "Progetto Wheelchair Rugby: Miglioramento delle capacità neuromuscolari residue in atleti disabili nella pratica sportiva del rugby in carrozzina" Available online at: http://community.oiconlus.it/civitasvitae/files/2015 /11/Ultimo-progetto-WCR-Masiero-Rugby.pdf

10. Van der Scheer JW, De Groot S, Veeger RJK, Van der Woude LH. Can a 15-m overground wheelchair sprint be used to assess wheelchair-specific anaerobic work capacity? Med Eng Phys 2014Vol 36, No.4, pag. 432-438.

11. Boninger ML, Koontz AM, Sisto SA,et al. Pushrim biomechanics and injury prevention in spinal cord injury: Reccomendaions based on CULP-SCI investigations J Rehabil Res Dev 2005;42:9-20.
12. Haydon DS, Pinder AR, Grimshaw PN, Robertson WSP. Overground Propulsion Kinematics and Acceleration in Elite Wheelchair Rugby. International Int J Sports Physiol Perform 2017:123.

13. Van der Woude LHV, Veeger DJ, Rozendal RH. Seat Height in handrim wheelchair propulsion. J Rehab Res Devel 1989;26:31-50.

14. Requejo PS, Mulroy SJ, Ruparel P, et al. Relationship Between Hand Contact Angle and Shoulder Loading During Manual Wheelchair Propulsion by Individuals with Paraplegia. Top Spinal Cord Inj Rehabil 2015;21:313-24.

Submitted: February 15, 2020 Accepted for publication: March 03, 2020 